\title{
PIERWSI ROLNICY NA ZIEMI KOCIEWSKIEJ \\ - REFLEKSJA Z NAJNOWSZYCH ODKRYĆ ARCHEOLOGICZNYCH
}

\author{
FIRST FARMERS OF THE KOCIEWIE LAND - A REFLECTION AFTER \\ NEW ARCHAEOLOGICAL DISCOVERIES
}

\section{Marian Kochanowski}

\author{
Muzeum Archeologiczne w Gdańsku \\ ul. Mariacka 25/26, 80-958 Gdansk, Poland
}

\begin{abstract}
The article is aimed at presentation of a newly discovered Linear Band Pottery settlement at Kościelna Jania, Smętowo Graniczne commune. The site was excavated during rescue works on the Al highway. It has been the largest settlement of this culture in the Starogard Lake District explored to date. In 21 excavated features, mainly settlement pits, numerous pottery sherds and animal bones (post-consumption remains) were found. Pottery technology and decoration make possible to link these materials with the Note phase and date them back to $4300-4000$ bc.
\end{abstract}

Temat artykułu został wybrany nieprzypadkowo. Z jednej strony dotyka bowiem istotnej z punktu widzenia studiów mezoregionalnych nad wspólnotami wezesnorolniczymi białej plamy, jaką było do niedawna w rozpoznaniu tego tematu Pomorze Gdańskie. Z drugiej strony odnosi się pośrednio do osoby Kazimierza Siuchnińskiego, który patronował moim poczynaniom badawczym tuż po studiach, gdy usiłowałem zlikwidować takąż archeologiczną białą plamę na ziemi chełmińskiej. Wówczas zarówno rady tegoż, jak i wsparcie poprzez udostępnienie studentów z roku, którego był opiekunem, do wstępnych prac weryfikacyjno-powierzchniowych stanowiły zaczyn późniejszego programu badawczego, co w efekcie spowodowało, że region leżący na szlaku z Kujaw wzdłuż Wisły nad wybrzeże Zatoki Gdańskiej jest obecnie jednym z lepiej rozpoznanych pod względem ilości pozyskanego materiału archeologicznego i stanu opracowania źródel'.

\footnotetext{
'Pozwolę sobie wymienić grupę moich mlodszych kolegów, w latach 1977-1978 jeszcze studentów: Marka Chłodnickiego, Pawła Dębowskiego, Ryszarda Kirkowskiego, Stanisława Kukawkę, Michała Madaja, Jacka Nowakowskiego i Zbigniewa Połczyńskiego. R. Kirkowski przejał po mojej przeprowadzce do Gdańska etat w Muzeum w Grudziądzu i wspólnie ze S. Kukawką z UMK w Toruniu kontynuowali prace badawcze nad epoką kamienia na ziemi chełmińskiej. Przytoczę również cytat z korespondencji w sprawie badań powierzchniowych, gdy K. Siuchniński pisał do mnie: „Pozostałaby jeszcze kwestia najważniejsza - merytoryczna.
} 
Południowe obszary Pomorza Gdańskiego, wzdłuż zachodniego brzegu Wisły (w czasach historycznych wykształciły się nazwy: ziemia kociewska, Kociewie bądź Pojezierze Starogardzkie), to enklawa trudno dostępna dla poczynan archeologicznych, między innymi poprzez silne zalesienie i trudne do eksploracji podłoże geomorfologiczne. Trzeba jednak stwierdzić, że do niedawna ${ }^{2}$ nie stanowiła pola zainteresowań badawczych dla jakiegokolwiek okresu pradziejów; liczny materiał źródłowy pochodził z działań ratowniczych, przypadkowych odkryć bądź danych archiwalnych, nierzadko jeszcze $z$ XIX w. Dla omawianych tu przeze mnie najnowszych odkryć, związanych z pobytem na Kociewiu plemion wczesnorolniczych, powinienem dla rozwinięcia tego zagadnienia przytoczyć uwagę O. Felczaka: „Powodem tak niekorzystnej sytuacji była jednokierunkowość poczynań naukowych zarówno w okresie międzywojennym, jak i powojennym, ograniczających się jedynie do studiów nad kulturą rzucewską wytworzoną przez ludność bytującą w pasie nadmorskim w schylkowym neolicie. Szczególnie zauważalny byl brak istotnych informacji źródłowych z południowej części Pomorza Gdańskiego, tj. Pojezierza Starogardzkiego. [...] Stąd też wszystkie publikacje omawiające między innymi zagadnienie neolitu nad dolną Wisłą ograniczały się do bardzo ogólnych i lakonicznych sformułowań na ten temat"

Niezależnie od archiwalnego porządkowania danych źródłowych z młodszej epoki kamienia i prowadzonych badań wykopaliskowych ${ }^{4}$, bardzo istotnym faktem stało się realizowanie od kilku lat szerokopłaszczyznowych badań ratowniczych na planowanej trasie autostrady A-1 w pasie od okolic Pruszcza Gdańskiego poprzez duże połacie Pojezierza Starogardzkiego aż na południe województwa. Działania te stały się niepowtarzalną szansą w miarę kompleksowego rozpoznania osadnictwa w przekroju całych pradziejów na niespotykaną dotąd skalę - pozyskano bowiem artefakty od schylkowego paleolitu po późne średniowiecze z osad i cmentarzysk; w większości były to stanowiska wielokulturowe. Nie miejsce tu na szczegółowe uzasadnianie rangi prowadzonych na A-1 od 1998 r. prac wykopaliskowych, z których materiały zostają sukcesywnie, pomimo

Z Pana informacji wnoszę, iż planowane badania będą miały charakter »archeologicznego zdjęcia terenu«, rodzaju spisu z natury wobec prawie zupełnego braku danych (odpowiednio uszczegółowionych) z wcześniejszych poczynań. [...] Nie wchodząc w szczegóły, pragnałbym jednak zwrócić tutaj uwagę na kilka podstawowych warunków prawidłowego zrealizowania akcji: a) odpowiednie podkłady mapowe, minimum mapy topograficzne w skali 1:25 000, ewen. dalsze o treści innej, jak geomorfologia, gleby etc.; b) odpowiedni, tj. rozszerzony kwestionariusz pytań w stosunku do tradycyjnego, przewidujący również opis elementów środ. naturalnego, elementów nieuwidocznionych na mapach (z reguły zgeneralizowanych); c) właściwe „,spreparowanie" dokumentacji opisowej i ilustracyjnej. Piszę zapewne o sprawach oczywistych, choć niezmiernie ważnych akurat w momencie życiowego startu" (list adresowany z Poznania 20 marca 1977 r.).

${ }^{2}$ Przed prawie ćwierćwieczem, w 1980 r., powstał zespołowy projekt, prowadzony przez Olgierda Felczaka z Muzeum Archeologicznego w Gdańsku, którego celem jest: „odtworzenie przemian osadniczych w neolicie powstalych $w$ wyniku pojawienia się społeczności rolniczych na obszarze dużej części prawego dolnego Powiśla, w rejonie usytuowanym między górną i środkową Wierzycą a Wisłą wzdłuż odcinka Gniew Tczew" (Felczak, 1998, s. 9; 1984).

${ }^{3}$ Felczak 1998, s. 9. Por. także: Wiślański, 1975, zwłaszcza s. 9-15, 22, 23, 43, 44.

${ }^{4}$ Niestety, jedynie sporadycznie opublikowanych przez O. Felczaka; dotyczyly m.in. znalezisk ze stacjonarnych badań w Brodach Pomorskich, gm. Gniew. 
natłoku bieżących obowiązków Muzeum Archeologicznego w Gdańsku - głównego wykonawcy prac, oglaszane drukiem ${ }^{5}$, a związane są tematycznie również z epoką kamienia na tym terytorium. Pragnąłbym odnieść się do całkiem świeżych odkryć, potwierdzających ewidentnie fakt już zorganizowanego osadnictwa pierwszych, osiadłych plemion rolniczych na ziemi kociewskiej.

Prace wykopaliskowe o charakterze ratowniczym na stan. 124, według numeracji w ramach planowanej autostrady A-1, na jej 57 kilometrze dotyczyły administracyjnie miejscowości Kościelna Jania, stan.13 w gminie Smętowo Graniczne, niedaleko Skórcza. Tak jak i w przypadku wielu stanowisk na planowanej trasie A-1 odnosiły się do nowego odkrycia, w ramach penetracji powierzchniowej i wytypowanego do archeologicznych prac ratowniczych z uwagi na dużą wartość poznawczą przy jednoczesnym zagrożeniu zarówno przez ludzi, jak i przyrodę. Badania trwaly od pierwszej dekady września do początków listopada 2002 r. Ogółem przebadano płaszczyzną o szerokości do 60 metrów obszar około 165 arów.

Wiadomo było na podstawie dotychczasowych odkryć w latach 1998-2001 na trasie A-1 (Barłożno, numeracja autostradowa: 115, 118, 119, 121, 122 - Z. Ratajczyk, O. Felczak, M. Kochanowski; Olszówka 70 - Z. Borcowski), że znajdujemy się na obszarze zasiedlonym przez plemiona wczesnorolnicze, które zapewne zajęły tereny po starszych, lokalnych grupach ludzkich o koczowniczym typie egzystencji. Obecność tych drugich wynikalaby z luźnych, nie związanych z obiektami archeologicznymi znalezisk wyrobów krzemiennych.

Sam teren badań wykopaliskowych to północna i północno-zachodnia część rozległego wyniesienia (o kulminacji ok. 86 m n.p.m.), opadającego na zachód w stronę rozlewisk rzeczki Janka, od południa zamkniętego polodowcowymi, wytopiskowymi zarówno ciekami, jak i tzw. oczkami wodnymi. Dominuje w promieniu kilku kilometrów dość duża różnorodność form pagórkowatych, ukształtowanych ostatecznie w zlodowaceniu bałtyckim, z reliktami lasu mieszanego na wschód od stanowiska. Warstwę współczesnego humusu stanowiła glina silnie zbielicowana, lekko pylasta. Wypełniskami obiektów był w większości piasek lekko gliniasty barwy szaroczarnej lub szarobrązowej. Podłoże calca stanowiła glina o barwie pomarańczowobrązowej bądź piasek drobnoziarnisty, barwy żóltej lub żwirowaty o zabarwieniu brunatnym. Niestety, uwarunkowało to zły stan zachowania materiałów osteologicznych - tylko kilkanaście drobnych fragmentów kwalifikowało się do przeanalizowania. Nie udało się pozyskać materiałów palinologicznych z najbliższych okolic - w zabagnionych dolinkach oczek wodnych.

Przyjrzyjmy się pokrótce reliktom osadnictwa najstarszego, dotyczącego kultury ceramiki wstęgowej rytej. Ogółem natrafiono na 21 obiektów (ryc. 1-3, w przeważającej większości są to jamy. Szczegółowe dane ująłem - dla przejrzystości - w formie tabelarycznej (zob. s. 150-152).

Jak można przyjąć z rozpoznania tego - w dużej mierze dzięki możliwości badań szerokopłaszczyznowych - dość zwartego osadnictwa o wyraźnej preferencji dwóch

${ }^{5}$ Paner, Fudziński 2001. 
Kościelna Jania, gm. Smętowo Graniczne, stan. 13. Zestawienie obiektów

Kościelna Jania, site 13, Smetowo Graniczne commune. A listing of features

\begin{tabular}{|c|c|c|c|c|c|c|c|c|}
\hline $\begin{array}{l}\text { Numer } \\
\text { obiektu }\end{array}$ & Charakter & Ksztalt & $\begin{array}{c}\text { Wymiary } \\
(w \mathrm{~cm})\end{array}$ & $\begin{array}{l}\text { Zachowana } \\
\text { miąższość } \\
(w \mathbf{c m})\end{array}$ & $\begin{array}{l}\text { Inne } \\
\text { elementy }\end{array}$ & Treść wypelniska & Material KCWR ${ }^{1}$ & $\begin{array}{c}\text { Material z innych } \\
\text { kultur } \\
\text { archeologicznych }\end{array}$ \\
\hline 1 & 2 & 3 & 4 & 5 & 6 & 7 & 8 & 9 \\
\hline 1 & jama & kolisty & ok. 180 & 30 & skupisko kamieni & $\begin{array}{l}\text { szary piasek, lekko } \\
\text { gliniasty }\end{array}$ & 28 fr. cer. & - \\
\hline 2 & jama & nieregularny & $395 \times 160$ & 40 & skupisko kamieni & $\begin{array}{l}\text { szary piasek, lekko } \\
\text { gliniasty }\end{array}$ & $\begin{array}{l}48 \text { fr. cer., } 1 \text { krzem., } \\
\text { kości zwierzęce }\end{array}$ & - \\
\hline 3 & jama & owalny & $200 \times 150$ & 80 & $\begin{array}{l}\text { skupisko kamieni } \\
\text { oraz polepa } \\
\text { w spagowej } \\
\text { części }\end{array}$ & $\begin{array}{l}\text { dwie warstwy: } \\
\text { 1) szaroczarny lekko } \\
\text { gliniasty piasek, } \\
\text { 2) intensywnie czarny } \\
\text { lekko gliniasty piasek }\end{array}$ & $\begin{array}{l}91 \text { fr. cer., } 6 \text { sur. } \\
\text { krzem., kości zwierzęce, } \\
\text { węgiel drzewny, polepa }\end{array}$ & $W E Z^{2}$ (1 fr. cer.) \\
\hline 9 & jama & owalny & $280 \times 230$ & 14 & & $\begin{array}{l}\text { szarobrązowy piasek } \\
\text { lekko gliniasty, } \\
\text { miejscami węgielki } \\
\text { drzewne }\end{array}$ & & $\begin{array}{l}\text { neolit ( } 1 \text { fr. cer) } \\
\text { WEŻ ( } 1 \text { fr. cer.), } \\
\text { krzemień }\end{array}$ \\
\hline 12 & jama & nieregularny & $190 \times 140$ & 5 & & $\begin{array}{l}\text { szarobrązowy piasek } \\
\text { lekko gliniasty }\end{array}$ & 2 fr. cer. & WEŻ ( 3 fr. cer.) \\
\hline 17 & jama & kolisty & 130 & 20 & & $\begin{array}{l}\text { szaroczarny piasek } \\
\text { lekko gliniasty }\end{array}$ & 2 fr. cer., 1 krzemień & \\
\hline 36 & jama & kolisty & $190 \times 200$ & 4 & & $\begin{array}{l}\text { szaro-brązowo-czarny } \\
\text { piasek lekko gliniasty }\end{array}$ & & $\begin{array}{l}\text { neolit ( } 1 \text { fr. cer.), późne } \\
\text { średn. ( } 1 \text { fr. cer.) }\end{array}$ \\
\hline 42 & $\begin{array}{l}\text { skupisko } \\
\text { kamieni }\end{array}$ & nieregularny & $700 \times 400$ & & $\begin{array}{l}\text { skupisko kamieni } \\
\text { o średnicy } \\
5-45 \mathrm{~cm}\end{array}$ & $\begin{array}{l}\text { pomiędzy kamieniami } \\
\text { szary piasek } \\
\text { drobnoziarnisty }\end{array}$ & $\begin{array}{l}139 \text { fr. cer., } 1 \mathrm{fr} \\
\text { krzemienia }\end{array}$ & WEŻ ( 9 fr. cer.) \\
\hline
\end{tabular}




\begin{tabular}{|c|c|c|c|c|c|c|c|c|}
\hline 1 & 2 & 3 & 4 & 5 & 6 & 7 & 8 & 9 \\
\hline 43 & jama & owalny & $190 \times 140$ & 10 & & $\begin{array}{l}\text { szary piasek } \\
\text { przemieszany } \\
\text { z brązowym piaskiem } \\
\text { lekko gliniastym }\end{array}$ & 29 fr. cer., 1 krzemień & WEŻ (3 fr. cer.) \\
\hline 44 & jama & owalny & $250 \times 200$ & 77 & & $\begin{array}{l}1 \text { - szary piasek lekko } \\
\text { gliniasty, } \\
2 \text { - szaroczarny piasek } \\
\text { lekko gliniasty }\end{array}$ & $\begin{array}{l}43 \text { fr. cer., } 1 \text { fr. wióra } \\
\text { krzem., } 13 \text { fr. krzemieni, } \\
\text { polepa }\end{array}$ & WEŻ (9 fr. cer.) \\
\hline 45 & $\begin{array}{l}\text { skupisko } \\
\text { kamieni }\end{array}$ & nieregularny & $400 \times 150$ & & $\begin{array}{l}\text { skupisko kamieni } \\
\text { o średnicy } \\
10-35 \mathrm{~cm}\end{array}$ & $\begin{array}{l}\text { pomiędzy kamieniami } \\
\text { szary piasek } \\
\text { drobnoziamisty }\end{array}$ & 5 fr. cer. & WEŻ (2 fr. cer.) \\
\hline 55 & jama & kolisty & 120 & 23 & & $\begin{array}{l}\text { szary piasek lekko } \\
\text { gliniasty }\end{array}$ & 2 fr. cer, 1 krzemień & WEŻ (4 fr. cer.) \\
\hline 56 & jama & nieregularny & $300 \times 240$ & 20 & & $\begin{array}{l}\text { szarobrązowy lekko } \\
\text { gliniasty }\end{array}$ & & $\begin{array}{l}\text { KPL ( } 1 \text { fr. cer.) } \\
\text { WEŻ ( } 5 \text { fr. cer.) }\end{array}$ \\
\hline 58 & jama & nieregularny & $270 \times 180$ & 39 & & $\begin{array}{l}1 \text { - szaroczarny } \\
\text { piasek lekko gliniasty } \\
2 \text { - szary piasek lekko } \\
\text { gliniasty } \\
3 \text { - szarobrazzowy piasek } \\
\text { lekko gliniasty }\end{array}$ & 7 fr. cer. & $\begin{array}{l}1 \text { fr. cer.nieokreślonej } \\
\text { chronologii }\end{array}$ \\
\hline 60 & jama & elipsa & $60 \times 40$ & 8 & $\begin{array}{l}\text { miejscami ślady } \\
\text { spalenizny }\end{array}$ & $\begin{array}{l}\text { szary piasek lekko } \\
\text { gliniasty }\end{array}$ & & $\begin{array}{l}\text { neolit ( } 7 \text { fr. cer.) } \\
\text { WEŻ ( } 2 \text { fr. cer.) }\end{array}$ \\
\hline 62 & jama & owalny & $60 \times 30$ & 6 & & $\begin{array}{l}\text { szary piasek lekko } \\
\text { gliniasty }\end{array}$ & & $\begin{array}{l}\text { neolit ( } 1 \text { fr.cer.), } \\
\text { WEŻ ( } 1 \text { fr. cer.), } \\
\text { późne średn. ( } 1 \text { fr.cer.), } \\
\text { nieokreślona chron. } \\
\text { (1 fr. cer.) }\end{array}$ \\
\hline
\end{tabular}




\begin{tabular}{|c|c|c|c|c|c|c|c|c|}
\hline 1 & 2 & 3 & 4 & 5 & 6 & 7 & 8 & 9 \\
\hline 64 & jama & owalny & $140 \times 70$ & 9 & & $\begin{array}{l}\text { szary piasek lekko } \\
\text { gliniasty }\end{array}$ & 10 fr. cer., 1 krzemień & WEŻ (l fr. cer.) \\
\hline 70 & jama & nieregularny & $230 \times 120$ & 16 & & $\begin{array}{l}\text { szaroczarny piasek } \\
\text { lekko gliniasty }\end{array}$ & 5 fr. cer. & \\
\hline 72 & jama & kolisty & 120 & 17 & & $\begin{array}{l}\text { szarobrązowy piasek } \\
\text { lekko gliniasty }\end{array}$ & $14 \mathrm{fr}$. cer. & \\
\hline 73 & jama & elipsa & $120 \times 70$ & 10 & & $\begin{array}{l}\text { szarobrązowy piasek } \\
\text { lekko gliniasty }\end{array}$ & 1 fr. cer. & \\
\hline 74 & jama & owalny & $90 \times 60$ & 18 & & $\begin{array}{l}\text { szarobrazowy piasek } \\
\text { lekko gliniasty }\end{array}$ & & $\begin{array}{l}\mathrm{KPL}^{3} \text { ( } 7 \text { fr. cer.), późne } \\
\text { średniowiecze } \\
\text { ( } 1 \text { fr.cer.), nieokreślona } \\
\text { chronol. ( } 10 \text { fr. cer.), } \\
\text { kości zwierzęce }\end{array}$ \\
\hline
\end{tabular}

${ }^{1}$ KCWR - kultura ceramiki wstęgowej rytej; ${ }^{2}$ WEŻ - wczesna epoka żelaza; ${ }^{3} \mathrm{KPL}$ - kultura pucharów lejkowatych. 


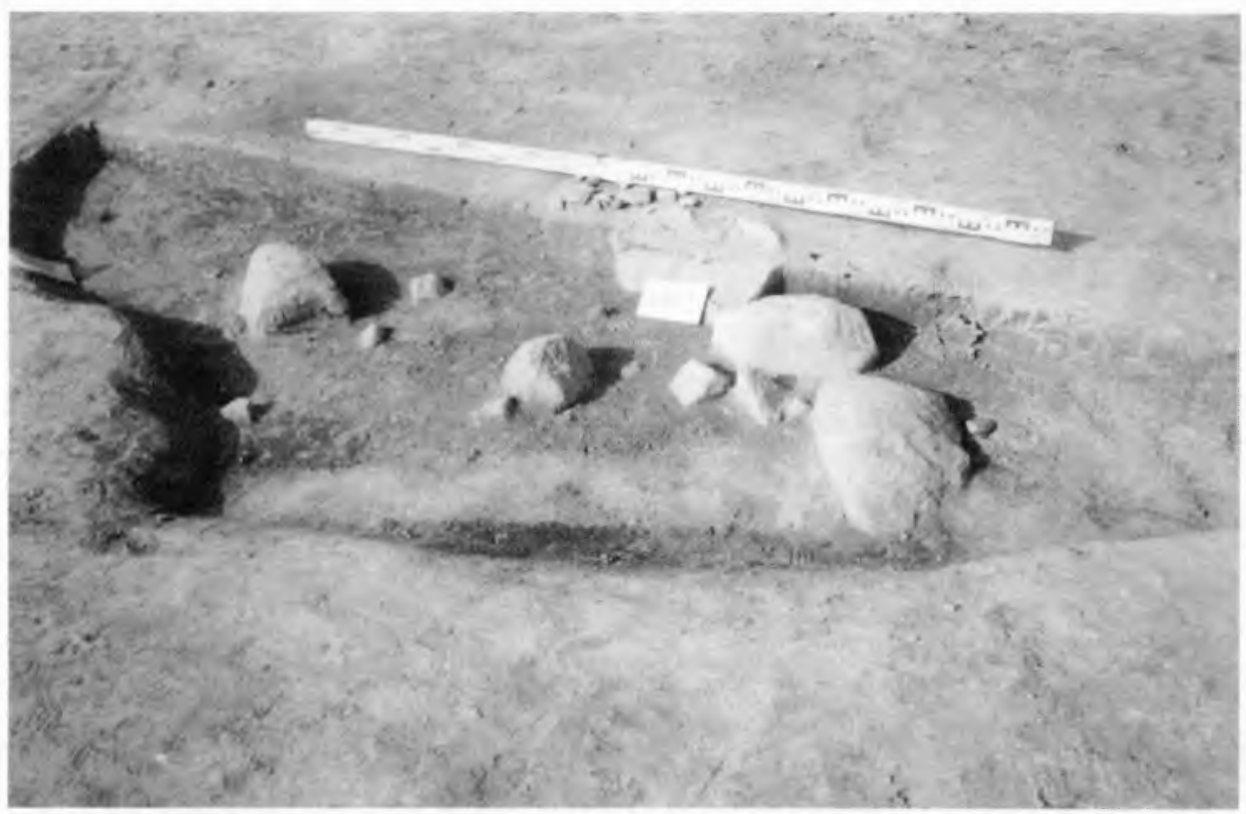

Ryc. 1. Kościelna Jania, gm. Smętowo Graniczne, stan. 13. Rzut poziomy obiektu nr 2 w czasie eksploracji części południowej z zaznaczająca się regularną warstwą kamieni - widok z N-E. Fot. J. Jarzęcka

Fig. 1. Kościelna Jania, site 13, Smętowo Graniczne commune. Plan of feature 2 during exploration of its south part containing a regular stone layer. A view from NE. Photo: J. Jarzęcka

horyzontów kulturowych, jest to reliktowo zachowany układ obiektów, będących śladami bytności plemion wczesnoneolitycznych oraz ludności z czasów wczesnej epoki żelaza. gdy obszar wyniesienia wykorzystano zarówno na cele sepulkralne, jak i wyraźnie (piec, jamy odpadkowe) egzystując w celach codziennej egzystencji.

Liczba obiektów, ich rozmieszczenie nie skłaniają do innych uogólnien, wskazuje na to zły stan zachowania większości z nich; ponadto ponad połowa $\mathrm{z}$ tych śladów osadniczych nie posiada wystarczających wyznaczników (źródeł ruchomych), pozwalających na uściślenie chronologii czy charakteru danego obiektu.

W przypadku osadnictwa związanego z cyklem kultur wstęgowych możemy opierać się w zasadzie na pozyskanych artefaktach: ułamkach ceramiki naczyniowej, wyrobach i półwytworach krzemiennych, kamieniach ze śladami obróbki (?), ułamkach polepy, nielicznych pokonsumpcyjnych kościach zwierzęcych. Na tym etapie analizy można przyjąć następujące ustalenia: bardzo wartościowy jest zespół ułamków ceramiki, datowanej dość pewnie poprzez liczne analogie z terenu ziemi chelmińskiej, Kujaw czy obszarów południowej Polski na wczesną fazę neolitu; naczynia tego typu wytwarzała ludność kultury ceramiki wstęgowej rytej, a dość typowy sposób ozdabiania ścianek zewnętrznych, jak też szczegóły technologiczne (kształt, zastosowana domieszka, wypał, grubość ścianek itp.) pozwalają odnieść chronologicznie ten zespół fragmentów naczyń 


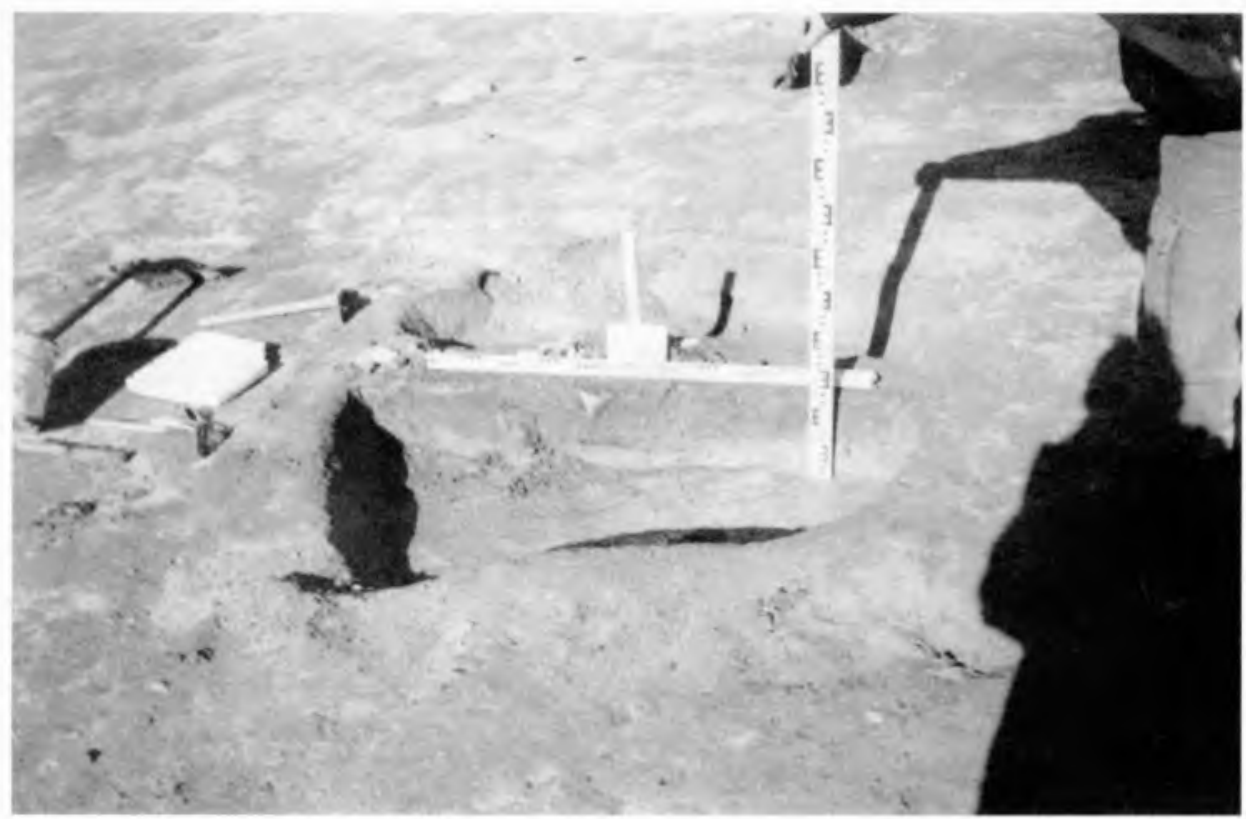

Ryc. 2. Kościelna Jania, gm. Smętowo Graniczne, stan. 13. Profil obiektu nr 17 w jego S części, po eksploracji, widok z S. Fot. J. Jarzęcka

Fig. 2. Kościeina Jania, site 13, Smętowo Graniczne commune. Section of feature 17 in its south part after exploration. A view from S. Photo: J. Jarzęcka

do dat bezwględnych ok. 4300-4000 p.n.e. (ryc. 4-5). Dominuje ceramika delikatna o grubości ścianek do $0,4 \mathrm{~cm}$, powierzchnie są starannie wyrównywane; naczynia grubej roboty są z reguły chropowate. Formy wskazują na małe naczynia typu czarki czy misy, występują ponadto typowe naczynia gospodarcze - zasobowe.

Materiał został odkryty w obrębie kilkunastu obiektów - w jamach o wyraźnie osadniczym charakterze - brak tu jednak innych śladów, zwłaszcza reliktów domostw użytkowanych przez tę ludność. W tym kontekście wyróżnia się kilka wyrobów krzemiennych, a zwłaszcza dobrze zachowany wiór z krzemienia importowanego, kilkanaście półwytworów krzemiennych i surowca.

Nieliczny, pochodzący z kilku obiektów materiał w postaci ułamków ceramiki dotyczy osadnictwa ludności kultury pucharów lejkowatych z charakterystycznym typem ornamentu żłobków pionowych dookolnych pod krawędzią wylewu i specyficzną dla tej kultury technologią produkcji naczyń. Egzystencja ludności tej kultury dotyczy połowy III tysiąclecia p.n.e.

Stanowisko nr 13 w Kościelnej Jani zostało rozpoznane co do zasięgu użytkowania i okresu eksploatacji tego obszaru. Zarówno studia archiwalne, jak i badania terenowe pozwalają na jednoznaczne potwierdzenie, że łagodne wyniesienia w ciągu od Barłożna po Kamionkę były zagospodarowane już od momentu penetracji i wyboru w celu osiadłego 


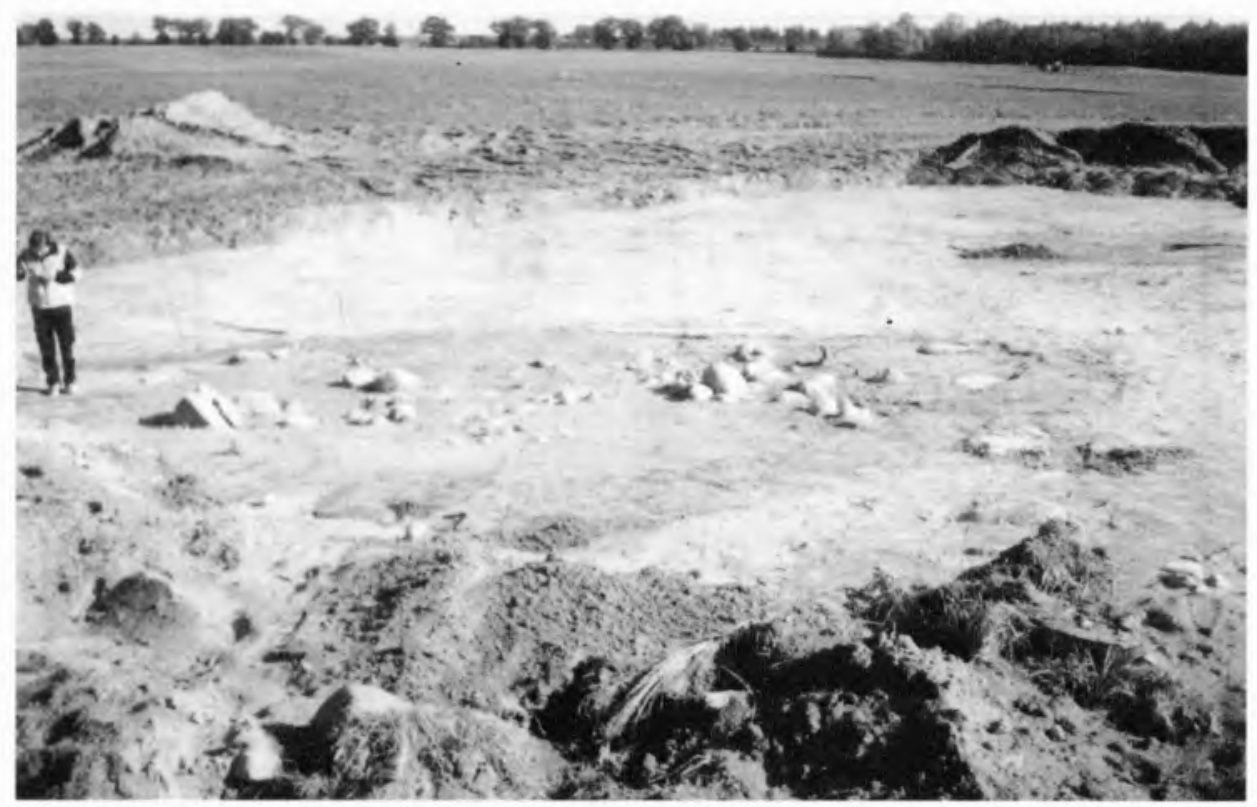

Ryc. 3. Kościelna Jania, gm. Smętowo Graniczne, stan. 13. Rzut obiektu nr 42 po wstępnym oczyszczeniu, przed wykonaniem dokumentacji rysunkowej, widok z S-W. Fot. J. Jarzecka

Fig. 3. Kościelna Jania, site 13, Smętowo Graniczne commune. Section of feature 42 after initial cleaning up, before drawing. A view from SW. Photo: J. Jarzęcka

trybu życia przez pierwsze plemiona rolnicze. Sprzyjała temu przyroda - wijąca się rzeczka Janka, liczne polodowcowe oczka wodne, mnogość lasów z egzystującą tam zwierzyna. Obecność tych plemion została zarejestrowana na tak dużą skalę dopiero w związku $\mathrm{z}$ akcją ratowniczych badań wykopaliskowych na trasie przyszłej autostrady A-1. Te stanowiska dotyczą okresu od połowy V tysiąclecia p.n.e. (ludność kultury ceramiki wstęowej rytej) po połowę IV tysiąclecia (ludność kultury ceramiki wstęgowej kłutej). Obecność tego ostatniego kręgu kulturowego nie została odkryta w Kościelnej Jani, natrafiono na nią zaś w odległym o kilkaset metrów Barłożnie (stan. 121 na A-1). Kolejna faza rozwoju tego mikroregionu związana jest z plemionami kultury pucharów lejkowatych, których obecność na naszym stanowisku zaznaczyła się jedynie sporadycznie. Główne centrum osadnictwa z zachowanymi reliktami domostw odkryto w Barłożnie ${ }^{6}$.

Mogę stwierdzić, iż wstępnie postawiona teza O. Felczaka ${ }^{7}$, jako konkluzja odkryć Z. Bagniewskiego, a wskazująca na możliwość przetrwania izolowanych środowiskiem naturalnym grup łowców-zbieraczy, reprezentujących cechy populacji mezolitycznych w pohudniowej części Pojezierza Kaszubskiego, wykazywała inne cechy zagospodarowania

Paner, Fudziński, Godon 1998, s. 17, 18.

Felczak 1998, s. 17, 18. 


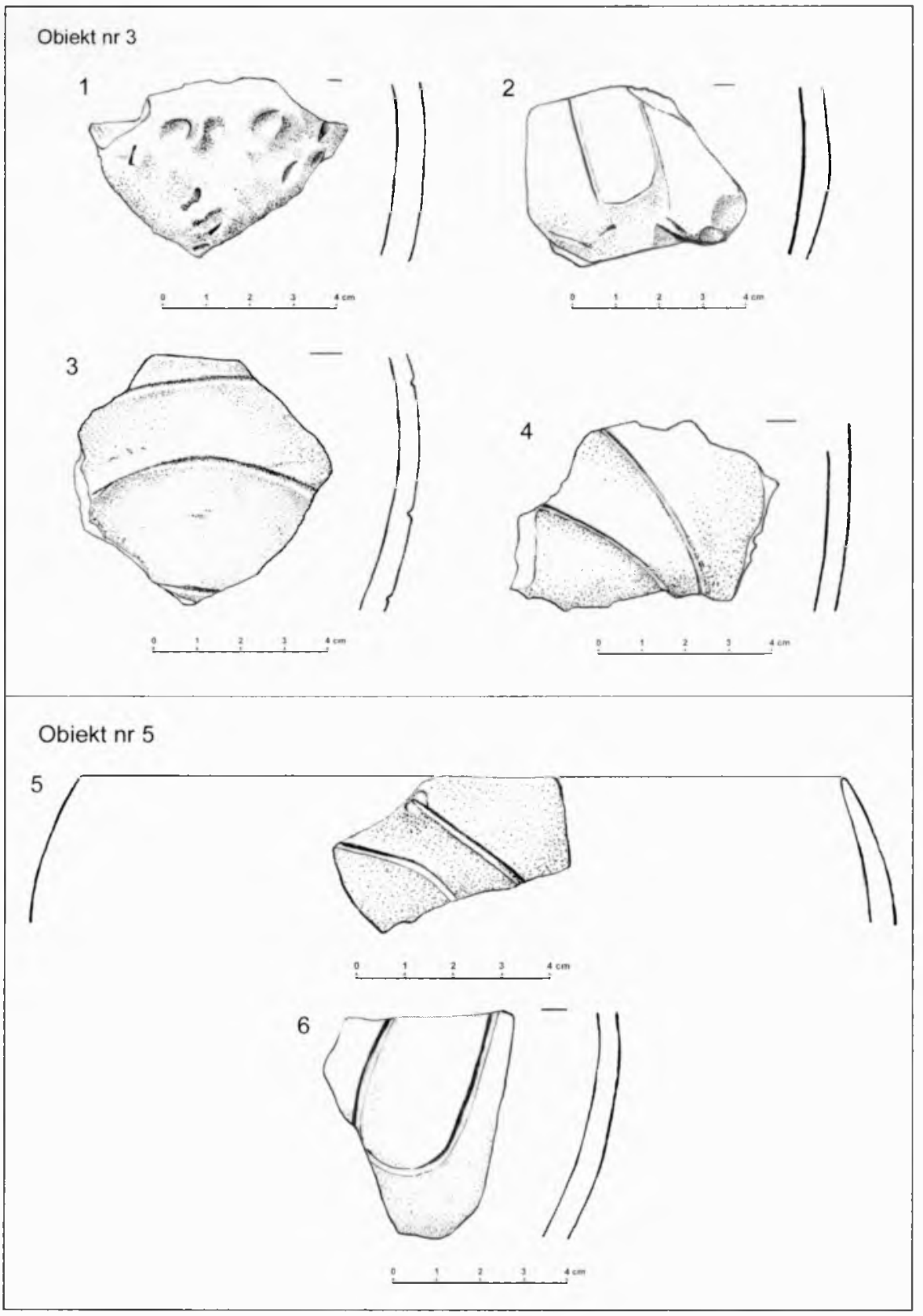

Ryc. 4. Kościelna Jania, gm. Smętowo Graniczne, stan. 13. Wybór ułamków ceramiki naczyniowej z obiektów nr 3 i 5

Fig. 4. Kościelna Jania, site 13, Smętowo Graniczne commune. Selection of pottery fragments from features 3 and 5 


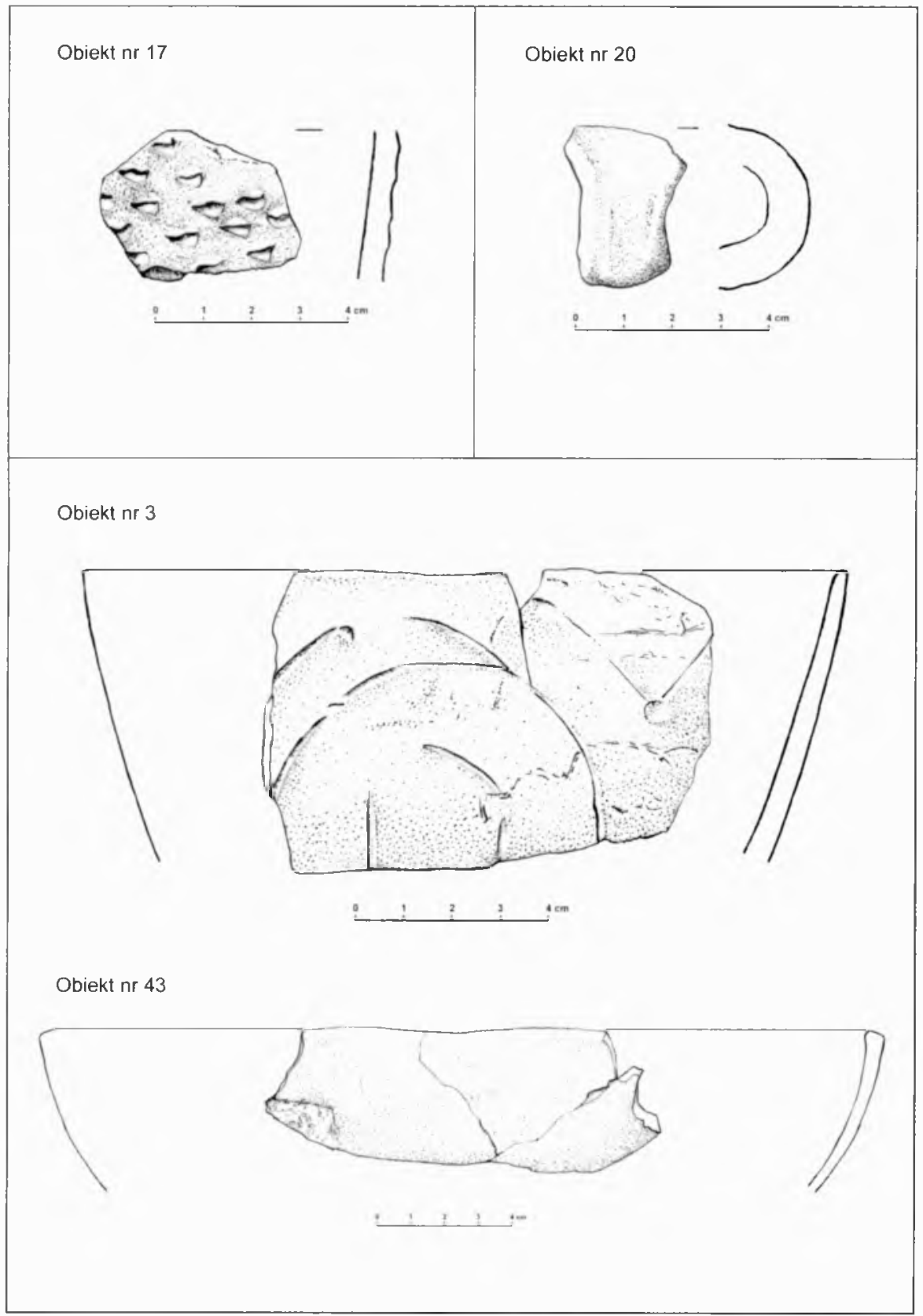

Ryc. 5. Kościelna Jania, gm. Smętowo Graniczne, stan. 13. Wybór ułamków ceramiki naczyniowej z obiektów nr $3,17,20,43$

Fig. 5. Kościelna Jania, site 13, Smętowo Graniczne commune. Selection of pottery fragments from features 3 , 17,20 , and 43 
w tym okresie na Pojezierzu Starogardzkim, dzięki czemu w konkluzji autor sugerował istniejąca tu pustkę osadnicza, trwającą nawet do 2000 lat - wobec napływu nowych materiałów źródłowych podległo istotnej z punktu widzenia nowych odkryć archeologicznych weryfikacji. Nawet uwzględniając, iż $\mathrm{O}$. Felczak miał na myśli jedynie rejon północnej części Kociewia (znad Jez. Rokickiego).

Obraz osadnictwa wczesnoneolitycznego stał się znacznie pełniejszy od chwili okazjonalnego podsumowania w 1983 r. stanu wiedzy o epoce kamienia na Pomorzu Gdańskim i dość kategorycznym stwierdzeniu: „Dotychczasowy stan badań nad początkami młodszej epoki kamienia pozwala stwierdzić, że pierwszymi osadnikami nowych czasów byli dopiero przedstawiciele kultury pucharów lejkowatych. Na Pomorze Wschodnie prawdopodobnie nie dotarła ludność tzw. kultur naddunajskich. Istotnym powodem były warunki geomorfologiczne. Zespół moren czołowych na Pojezierzu Kaszubskim i zwarta formacja leśna Borów Tucholskich utrudniała i ograniczała od zachodu napływ osadników z południa. Jedynym szlakiem komunikacyjnym, którym mogli się przesuwać pierwsi rolnicy, była Wisła. Znad dolnej Wisły znamy luźne wyroby kamienne, które przypisać możemy tzw. kulturom południowym. Brak jednak innych śladów potwierdzających ich obecność. Nie ma też na Pomorzu Wschodnim gleb (lessów, pseudoczarnoziemów, bielic z utworów pylastych), które pozwalały na prowadzenie gospodarki typowej dla plemion południowych" ${ }^{8}$. Widać wyraźnie, jak wiele w okresie ostatnich dwudziestu lat zmieniło się w ilości i jakości pozyskanych źródeł archeologicznych dla omawianego w niniejszym szkicu terytorium.

Szczegółowych studiów i dalszych rozstrzygnięć w trakcie prac terenowych wymaga wyjaśnienie kwestii pojawienia się trwalszych - kilkusezonowych osad plemion „wstęgowych" w kontekście kontaktów pierwszych grup rolniczych z grupami miejscowymi o cechach lowiecko-rybackich, choć oczywiste jest, że zasobne w faunę i florę lasy zdeterminowaly charakter egzystencji lokalnych, koczowniczych grup ludzkich.

\section{BIBLIOGRAFIA}

Felezak O.

1984 Zagadnienie neolityzacji Pomorza Gdańskiego w aspekcie nowych odkryć archeologicznych między Wierzycq a Wisla, (w:) LX Sesja Pomorzoznawcza, Gdańsk, 22-23111 1984, s. 10-19.

1998 Problem najstarszego osadnictwa neolitycznego w rejonie Jeziora Rokickiego, „Pomorania Antiqua" t. XVII, s. 9-29.

Felczak O., Król D.

1983 Pierwsi osadnicy na Pomorzu Wschodnim, ,Z otchłani wieków” nr 1-2, s. 16-20.

Paner H., Fudziński M.

2001 Ratownicze badania archeologiczne w obrębie autostrady A-1 na terenie województwa pomorskiego [Sum.: Rescue archaeology along the route of the Al Motorway in the Voivodship of Pomorania], „Pomorania Antiqua” t. XVIII, s. 7-48.

${ }^{8}$ Felczak, Król 1983,s. 17 
2003 Ratownicze badania archeologiczne w obrębie autostrady A-I na terenie województwa pomorskiego w roku 2000 [Sum.: Rescue Excavations in 2000 Along the Route of the A I Motorway in the Voivodship of Pomorania], „Pomorania Antiqua” t. XIX, s. 7-36.

Wiślański T.

1975 Stan i potrzeby badawcze epoki kamienia i poczatków epoki brazu na Pomorzu Wschodnim [Sum.: The Present State of and Need for Reasarch on the Stone Age and Early Bronze in East Pomerania], „Pomorania Antiqua” t. VI, s. 9-53.

\section{FIRST FARMERS OF THE KOCIEWIE LAND - A REFLECTION AFTER NEW ARCHAEOLOGICAL DISCOVERIES}

\section{Summary}

The article is aimed at presentation of the newest archaeological discoveries of the earliest early Neolithic farmers' sites in the Gdańsk Pomerania. An empirical data from the Neolithic in this region has been scare until very recently and has originated from rescue and accidental discoveries as well as archive documents, often dated back to the $19^{\text {th }}$ century. This situation was caused by one-sided research interests, both before and after the World War II, focused almost exclusively on the Rzucewo culture created by communities exploring the Baltic seaside in the late Neolithic. A lack of substantial evidence from the south part of the Gdańsk Pomerania, namely from the Starogard District Lake, was striking.

It was not earlier than a huge rescue operation on the Al highway started that recognition of a whole range of sites had been possible. Numerous settlements and cemeteries from the Upper Palaeolithic to the late Middle Ages have been discovered. Empirical data from this campaign is systematically published (e.g. Paner, Fudziński 2001).

The excavations at Kościelna Jania, site 13, Smętowo Graniczne commune, were undertaken between early September and early November 2002. A strip of up to 60 meters in width comprising 165 ares in total was excavated. It is located on the north and the north-west part of a large eminence (ca. 86 meters above see level) sloping down towards a floodplain of the Janka river, which itself is surrounded by small streams and lakelets from the south.

All artefacts and features of the Linear Band Pottery Culture are presented in the article in a tabular form. The excavations revealed 21 features, mostly pits. A small number of features, their distribution and poor preservation prevent from formulating any generalisations. Additionally, most than half of them was lacking any discriminant elements (artefacts) rendering impossible a chronology specification and function of particular features.

Neolithic pottery from Kościelna Jania has been dated back, in most cases, to the Note phase of the Linear Band Pottery Culture by a means of numerous analogies from the Chelmno Lands, Kujavia and south Poland areas. A pretty typical way of outer wall surface decoration as well as technological details (shape, temper, wall thickness, etc.) is indicative of their chronology between ca. $4300-4000$ bc. A dominant fineware pottery was thin-walled (up to $4 \mathrm{~mm}$ in width) with careful surface finish while the coarseware ceramics had rough surface finish. The most typical were small bowls and cups in addition to large household vessels. In some features, fragments of the Funnel Beaker pottery (decorated by vertical bars underneath the vessel edge and produced in typical technology for this culture), dated back tentatively to the mid of the $3^{\text {rd }}$ millenium bc, were discovered.

Results of archaeological investigations of the Al highway section conducted to date indicate that a zone of easy eminences between Barłożyn (sites 115,118,119,121,122 according to the highway recording system) and Kamionka was occupied by early farmers already in the $5 \mathrm{t}^{\mathrm{h}}$ millennium BC. These communities undoubtedly replaced local hunter-gatherers practising a mobile way of life and built relatively stable settlements occupied over a few seasons. A closer examination of mutual relationships between early farmers and local foragers is only possible when more field works are undertaken. 